\title{
Editorial
}

\section{Industrial benefits and respiratory diseases}

Two categories of compensation are available to an individual in the United Kingdom when the question of disability due to an occupational cause arises. The first category is claimed through the process of common law and the second through the provisions of the Social Security Act 1975, which demands that the person must be suffering from a prescribed disease. The two systems are separate and the State system is not influenced in any way by what occurs in the courts. The total expenditure by the Department of Health and Social Security (DHSS) on social security (including retirement pensions) is in the region of $£ 40$ billion but only $1 \%$ of this somewhat staggering sum is spent on industrial injuries benefit. Since the prescribed respiratory diseases form only part of that $1 \%$, why is there so much controversy surrounding the compensation of occupational respiratory disease? One contributory reason may be the widespread lack of understanding of how the system operates.

The term pneumoconiosis medical panel has recently been replaced in official language by "medical boarding centre (respiratory diseases)," abbreviated to MBC (resp diseases). There are eight such centres covering the whole country: Cardiff, Glasgow, London, Manchester, Newcastle, Sheffield, Stoke, and Swansea. They are staffed by full time medical officers of the DHSS, and part time doctors, who are usually retired chest consultants, former full time members, or occupational health physicians with experience of respiratory medicine. From them are drawn the doctors who constitute the specialist adjudicating medical authorities (referred to subsequently as AMAs) and who make up the "special medical boards" consisting of two doctors. Pneumoconiosis medical boards are responsible for the medical decisions on diagnosis and assessment of disability in connection with disablement benefit claims for prescribed respiratory diseases. There are two distinct parts to the decision making process, one purely medical and the other adjudication. They also advise the local adjudicating officer about cause of death in applications for industrial death benefit. In addition, they still have some duties concerned with examining

Address for reprint requests: Dr FG Ward, Department of Health and Social Security, Friars House, 157-168 Blackfriars Road, London SE1 8EU. workers exposed to dusts in certain industries both before and during employment. As medical adjudicating authorities they constitute a statutory body under the Social Security Act. A consequence of this is that once they have reached a decision it is binding in law and cannot be altered except by appeal through the appropriate channels or where fresh evidence suggests a mistake about some material fact.

Decisions are reached on "balance of probability"- that is, that it is more likely than not that the disease in question is or is not present and, if present, is due to occupation. This is different from "beyond all reasonable doubt," which would be expected in a criminal investigation; but it is also different from "benefit of the doubt." Confusion is increased when it is not appreciated that the adjudicating authorities have only two options open to them. They can, of course, answer "yes" or "no." They cannot record "don't know." If they conclude that on the available evidence it is not possible to say that it is more likely than not that the patient's disease is due to his or her occupation or that the diagnosis can be made, then it follows that the decision on diagnosis must be negative. Medical questions, of course, are frequently not as clear as that. There is seldom any doubt about occupational link in, for example, diseases linked with coalmining but the decision may be much more difficult in occupational asthma.

Occupations prescribed under industrial injury provisions may be found in the list of prescribed diseases; the relevant part is in the appendix to the DHSS leaflet Pneumoconiosis and Related Occupational Diseases ${ }^{1}$ (this booklet is being revised at present and does not include the most recently added diseases or occupational asthma). Pneumoconiosis is defined by Parkes as "the nonneoplastic reaction of the lungs to inhaled material or organic dust and the resultant alteration in their structure excluding asthma, bronchitis and emphysema."2 For purposes of the industrial injuries provisions it is defined somewhat differently as "fibrosis of the lungs due to silica dust, asbestos dust or other dust. The expression includes the condition of the lungs known as dust-reticulation." ${ }^{\text {Once a }}$ claim has been made (initially to the local office of the DHSS nearest to the claimant's home, on a special claim form) there are six questions to be answered: (1) Is the disease included in the schedule? (2) Is the dis- 
ease prescribed in relation to the claimant? (3) Is the claimant suffering from the disease? If the answers are "yes" there are additional questions: (4) What is the date of onset? (5) What is the degree of disablement? (6) Is the disease due to the claimant's employment?

Questions 1, 2, and 6 are dealt with by the local adjudicating officer (formerly the local insurance officer) and are not matters for the medical authorities. The adjudicating officer is also a statutory authority. Since answering these questions requires a detailed knowledge of occupational history and since that can be difficult to obtain for jobs done many years ago, the adjudicating officer's task is clearly a difficult one. Obtaining the necessary proof may well take some considerable time. A claim may fail at this stage without ever reaching the AMA's but there is a right of appeal and the claimant would then be referred to the Social Security appeal tribunal. When prescription has been settled in the claimant's favour he or she will be referred to the nearest medical boarding centre. In the case of a coalminer a radiograph would be taken and the claim could be turned down on scrutiny (with right of appeal to a special medical board). Otherwise the patient would be examined by two doctors (AMA). If patients are too ill to travel, arrangements are made to see them at home. The medical examination is conducted along familiar lines as in any chest clinic, and simple lung function tests are done. Patients claiming benenfit for asbestosis are usually referred for additional detailed physiological tests of lung function. In coming to their conclusions the AMA will have access to recent radiographs and hospital case notes with special reference to appropriate pathological reports. These notes are, of course, treated as confidential. The patient's permission for the release of the medical records is sought on the original claim form. Reports may also be sought from general practitioners or company doctors. In an appeal against a decision the claimant has a right to see all the evidence that the AMA used. Without the hospital case notes or other information decisions would have to be reached on available but inadequate evidence. Once the disease has been diagnosed the assessment of disability is based on the same clinical, physiological, and radiological evidence. There are no magic formulae and no secret tables. It is a question of judgment. If the AMA cannot reach a decision on its own a specialist report will be sought. This is perhaps most likely in cases of occupational asthma. The consultant approached is, of course, free to carry out whatever investigations he thinks necessary. The AMA's decision is given to the adjudicating officer, who informs the claimant and in new cases a report is sent to the general practitioner and to the consultant concerned if appropriate.

In assessments of disability due to pneumoconiosis, byssinosis, and mesothelioma the minimum disability is $10 \%$ and the increments go in steps of $10 \%$; benefit is paid as a weekly pension. For the other respiratory diseases benefit is paid as a lump sum if the disability is assessed as below $20 \%$. Many diseases not in themselves prescribed diseases-for example, chronic bronchitis and emphysema, are considered in assessing the total disability, and the effects of tuberculosis occurring in the presence of pneumoconiosis are treated as the effects of the pneumoconiosis. Various other benefits may be available to the claimants in particular circumstances, of which the Special Hardship Allowance is perhaps the best known. This is payable if the person cannot continue his or her regular occupation on account of the disease and is intended to make up some of the shortfall in earnings. Details of this and other additional benefits can be obtained from leaflets NI 3 and NI 6, available from DHSS local offices.

Three types of assessment may be given. A "provisional" assessment may be given where the AMA considers that it is not possible to predict the outcome. A "final" assessment may be given where the AMA finds that it is possible to predict the outcome and decides that the disablement will last for a finite period. A "final for life" assessment is made where it is concluded that the disablement is unlikely to change. A provisional assessment is usual, at least initially, in diseases other than occupational asthma and a final life assessment is more commonly used in cases of occupational asthma, where sensitivity is assumed to be lifelong whatever the severity of the asthma. It is customary to give high awards for cases of mesothelioma. AMAs do not, however, speculate about what might happen in the future and, in general, they are concerned with the disabling effects present at the time of the examination. In this respect they are in a quite different position from the doctor giving a report in a civil action who is asked to prognosticate about the future effects of a disease or injury. While AMAs take into account other diseases existing at the time of their assessment, pre-existing asthma is offset against the total effect of the occupational asthma and the pre-existing state in decisions about what level of disablement is attributable to the occupation. Contrary to widespread belief, however, those with a history of pre-existing asthma are quite entitled to claim benefit if they think that their condition has been made worse by their occupation.

Death benefit is payable to dependent relatives if an industrially caused disease can be shown to have been a material factor in causing death. In England and Wales the coroner is responsible for investigating cases of unnatural death and normally will arrange a postmortem examination. The thoracic organs are 
generally made available for examination by doctors from the medical boarding centre. Their function is to give an opinion to the adjudicating officer on whether occupational lung disease was a material factor in causing or materially accelerating death. The initial prescription questions still have to be answered when the person has not been seen in life and they may then be even more difficult. In the asbestos related diseases the coroner does not have to wait for the AMAs opinion since the delays are sometimes prolonged when detailed special histological reports are needed. It should be noted that social security benefits are completely independent of the coroner's investigations. In Scotland, where there are, of course, no coroners, a postmortem examination may be performed if the widow gives her consent. The thoracic organs are not generally required in cases of occupational asthma.

The right of appeal exists against AMAs' decisions on diagnosis and disablement. The appeal is to a medical appeal tribunal, which consists of a lawyer and two chest consultants with experience in occupational medicine. This tribunal is independent of the DHSS and there is no further right of appeal unless this is on a point of law and leave to appeal is granted by the tribunal or the commissioner, in which case the appeal is to the social security commissioners. There is an unrestricted right of appeal in all chest diseases but after a decision by a medical appeal tribunal there is no further right of appeal for two years in cases of pneumoconiosis and byssinosis. Appeals are made through the local office of the DHSS. In cases of fatal disease the appeal is made to a social security appeals tribunal, which is independent of the DHSS and consists of a lawyer, an employee's representative, and an employer's representative. Either the claimant or the Secretary of State can appeal to the social security commissioner on a point of law. Appeal tribunals must also come to a decision on balance of probabilities and not giving benefit of doubt.

In addition to the appeals procedures briefly outlined above, patients may apply for review of their assessment before it runs out if it is considered that their condition has deteriorated. To initiate such a review an application for "unforseen aggravation" is made and an examination by the AMA is arranged.

Diseases not already prescribed can be considered for prescription by the Industrial Injuries Advisory Council. The committee is composed of representatives of all sides of industry as well as medical members with specialist experience in occupational medicine or related disciplines. Their task is to review and to seek evidence from all sources, including individual members as well as corporate bodies. Written and oral evidence is considered and thereafter a report is produced with whatever recommendations seem appropriate. The government of the day then has to decide whether to accept or reject the findings.

As the number of cases of coal pneumoconiosis and silicosis has declined the importance of the asbestos related disorders has increased and, not surprisingly in view of the complex nature of the conditions, so have the apparent controversies. Given the type of constraints under which AMAs must operate a good occupational history is essential. The criteria for diagnosing asbestosis in the DHSS handbook are: (1) the characteristic bilateral basal crepitations; (2) radiological features of diffuse interstitial fibrosis in the lower halves of the lung fields $\left(45^{\circ}\right.$ oblique films are particularly helpful); (3) impairment of lung function consistent with a diagnosis of diffuse interstitial fibrosis. On the other hand, rapid progression, widespread crackles, and widespread radiological changes are features that might argue against the diagnosis. It is usually considered reasonable if the exposure has been slight to ask whether other diseases can be ruled out before the diagnosis of asbestosis is made, and if exposure has been substantial to consider whether asbestos can reasonably be excluded as a factor.

Lung biopsy for purposes of compensation alone cannot be justified-particularly where there is any possibility of mesothelioma. It is true that this diagnosis is a histological one but such proof in life is not always possible and is not essential. After death, however, histological confirmation is usually sought from suitable experts. Most would recognise that the presence of asbestos bodies in sputum merely indicates exposure to asbestos but what of more sophisticated techniques, such as lavage? In general, since the occupational history is usually known, they have little place in AMA's assessments. Electron microscopy is still essentially a research tool and not enough is known about normal variations in fibre counts, quite apart from the technical difficulties. In future possibly it will have a place when the occupational exposure is entirely unknown.

In April 1985 two new diseases were added to the list of prescribed diseases-bilateral diffuse pleural thickening, and cancer of the lung in those with evidence of asbestosis or of bilateral diffuse pleural thickening. Once again oblique films are helpful. Cancer of the lung with asbestosis has been accepted as a sequela of asbestosis for some time but now the disease is recognised in law with the additional cover providing benefit for more people. It is too early to say whether the scope for controversy has been increased or reduced by these changes.

Claims for occupational asthma have not so far provided the flood of cases that some expected. There are many reasons for this, no doubt including the fear of unemployment, but is it possibly not so common a disease as we thought? A recent report by the Industrial Injuries Council suggesting some changes in the 
scheme is under consideration at present.

An attempt has been made to explain how the medical boarding centres for respiratory diseases operate and how certain aspects of legislation affect their decisions. In the past two decades changes in the pattern of occupational lung diseases and improved understanding of their causation have been followed in time by changes in the law, which in turn have ensured that the procedure for compensation has been continuously modified rather than static. No system of compensation is likely to be perfect and no doubt medical boarding centres will live with controversy as the pneumoconiosis medical panels did before them. Whatever the defects, however, it is difficult at present to envisage any radically different system that would be able to deal with the work. What really matters is that the conditions should exist in which the adjudicating medical authorities and chest consultants can work together for the benefit of the patients.

FG WARD

Department of Health

and Social Security,

London SE1 8EU

The contents of this article represents the author's views alone and in no way commit the Department of Health and $\varrho$

Social Security.

\section{References and further reading}

1 Department of Health and Social Security. Pneu- ${ }^{\omega}$ moconiosis and related occupational diseases. London: DHSS, 1979. (Leaflet NI 226.)

2 Parkes WR. Occupational lung disorders. 2nd ed. $\exists$ London: Butterworths, 1982.

3 Britton MG, Hughes DTD, Phillips TJG. A guide to i compensation for asbestos related diseases. $\mathrm{Br}$ Med $\mathrm{J} V$ 1981;282:2107-11. 


\section{Notice}

\section{Thoracic medicine in the regions}

As long ago as 1960 the Standing Tuberculosis Advisory Committee, considering the future of the chest services, recommended that chest physicians and chest units should be part of the general hospital complex, and this advice was reinforced by the publication of the document The Future of the Chest Services by the Central Health Services Council (Ministry of Health) in 1968. This publication and in 1978 the Joint Committee on Higher Medical Training, Respiratory Medicine, both emphasised the fact that there was also a place for specialised thoracic units that would be responsible for special diagnostic problems, specialised investigations, research, and training of senior registrars. Generally, these units would be centred in major teaching centres and at least one would be required in each region.

Recently the British Thoracic Society and the Royal College of Physicians approved a document, Requirements for Thoracic Medicine, that provides guidance for staffing and for inpatient and outpatient facilities for thoracic medicine in district general hospitals.

In response to evident widespread lack of awareness about the more specialised aspects of thoracic medicine, the Council of the British Thoracic Society asked the Regional Representatives' Subcommittee to draw up an outline of the functions of a regional thoracic centre.

The resulting document was considered by the Council and adopted as official policy of the British Thoracic Society. It is reproduced below in the hope that it may be a helpful source of reference for administrators, clinicians, and others who have responsibility for the provision of thoracic medical services in each region, and that it may be of interest to others with similar responsibilities abroad.

SPECIAL FUNCTIONS OF THORACIC MEDICINE (NON-DISTRICT BASED)

Regional

Thoracic surgery

Unit for the care of cystic fibrosis

Bronchial challenge testing

Special aspects of occupational lung disease

Chronic ventilatory support
Supraregional

Participation in lung and heart/lung transplantation programmes Bronchoscopic laser therapy

Subregional

More specialised respiratory physiology

Body plethysmography

Exercise testing

Specialised bronchoscopy

Bronchial lavage

Screening for biopsy of mass lesions, transbronchial biopsy

Needle biopsy

High speed drill biopsy

Open lung biopsy

Oncology

Assessment for treatment

Liaison with thoracic surgery and radiotherapy

Cytotoxic chemotherapy

Lung pathology: specialised interpretation of small biopsy specimens Specialised imaging (computed tomography, magnetic resonance imaging, digital subtraction angiography)

At all levels there should be research and the teaching of undergraduates and postgraduates. Senior registrar training should rotate through regional units.

${ }^{1}$ British Thoracic Society. Requirements for Thoracic Medicine. Thorax 1984;39:400.

\section{Correction}

\section{Industrial benefits and respiratory diseases}

In the editorial by Dr FG Ward (April 1986;41:257) there is an error in the definition of pneumoconiosis quoted from $\mathrm{Dr}$ Raymond Parkes. The word mineral should appear instead of "material." The definition of pneumoconiosis should read: "the non-neoplastic reaction of the lungs to inhaled mineral or organic dust and the resultant alteration in their structure excluding asthma, bronchitis and emphysema." 